\title{
Contraceptive Use Among Women at Risk for Unintended Pregnancy in the Context of Public Health Emergencies — United States, 2016
}

\author{
Karen Pazol, PhD ${ }^{1}$; Sascha R. Ellington, $\mathrm{MSPH}^{1}$; Anna C. Fulton, $\mathrm{MPH}^{2}$; Lauren B. Zapata, PhD ${ }^{1}$; Sheree L. Boulet, DrPH ${ }^{1}$; Marion E. Rice, MPH ${ }^{2}$; \\ Shanna Cox, MSPH${ }^{1}$; Lisa Romero, DrPH ${ }^{1}$; Eva Lathrop, $\mathrm{MD}^{2}$; Stacey Hurst, $\mathrm{MPH}^{1}$; Charlan D. Kroelinger, $\mathrm{PhD}^{1}$; Howard Goldberg, PhD ${ }^{1}$; \\ Carrie K. Shapiro-Mendoza, $\mathrm{PhD}^{1}$; Regina M. Simeone, $\mathrm{MPH}^{2}$; Lee Warner, $\mathrm{PhD}^{1}$; Dana M. Meaney-Delman, MD ${ }^{2}$; Wanda D. Barfield, MD ${ }^{1}$; \\ Behavioral Risk Factor Surveillance System Family Planning Module Working Group
}

Ensuring access to and promoting use of effective contraception have been identified as important strategies for preventing unintended pregnancy (1). The importance of ensuring resources to prevent unintended pregnancy in the context of public health emergencies was highlighted during the 2016 Zika virus outbreak when Zika virus infection during pregnancy was identified as a cause of serious birth defects (2). Accordingly, CDC outlined strategies for state, local, and territorial jurisdictions to consider implementing to ensure access to contraception (3). To update previously published contraceptive use estimates* among women at risk for unintended pregnancy ${ }^{\dagger}$ and to estimate the number of women with ongoing or potential need for contraceptive services, ${ }^{\mathbb{S}, \boldsymbol{S}}$ data on contraceptive use were collected during September-December 2016 through the Behavioral Risk Factor Surveillance System (BRFSS). Results from 21 jurisdictions indicated that most women aged 18-49 years were at risk for unintended pregnancy (range across jurisdictions $=57.4 \%-76.8 \%$ ). Estimates of the number of women with ongoing or potential need for contraceptive services ranged from 368 to 617 per 1,000 women aged 18-49 years. The percentage of women at risk for unintended pregnancy using a most or moderately effective contraceptive method $^{* *}$ ranged from $26.1 \%$ to $65.7 \%$. Jurisdictions can use this information to estimate the number of women who might seek contraceptive services and to plan and evaluate efforts to

\footnotetext{
* State-based estimates of contraceptive use during the Zika response were from 2011-2013. https://www.cdc.gov/mmwr/volumes/65/wr/mm6530e2.htm.

$\dagger$ Women were considered at risk for unintended pregnancy unless they reported that they were not sexually active with a male partner, that they were currently pregnant or seeking pregnancy, that they would not mind being pregnant, or that they had a hysterectomy.

$\$$ Women with ongoing or potential need for contraceptive services were defined as those women considered at risk for unintended pregnancy who were not using permanent contraceptive methods (female sterilization or report of male partner vasectomy).

The number of women with ongoing or potential need for contraceptive services can be used to predict the number of women who might seek services, but does not represent unmet need for contraception because many of these women might already be using some method of contraception. https://www.guttmacher. org/sites/default/files/report_pdf/contraceptive-needs-and-services-2014_1.pdf.

** Most effective contraceptive methods are associated with a $\leq 1 \%$ failure rate during the first year of typical use; moderately effective contraceptive methods are associated with a $>1 \%-10 \%$ failure rate during the first year of typical use. These contrast with less effective methods, which are associated with a $>10 \%$ failure rate during the first year of typical use, and the use of no method, which is associated with an $85 \%$ pregnancy rate for the overall population of women of reproductive age. https://www.cdc.gov/reproductivehealth/contraception/index.htm.
}

increase contraceptive use. This information is particularly important in the context of public health emergencies, such as the recent Zika virus outbreak, which have been associated with increased risk for adverse maternal-infant outcomes $(2,4-6)$ and have highlighted the importance of providing women and their partners with resources to prevent unintended pregnancy.

BRFSS is a cross-sectional jurisdiction-specific, randomdigit-dialed, telephone survey that collects data on risk behaviors and preventive health practices among adult respondents living in the 50 states, the District of Columbia, Puerto Rico, Guam, and U.S. Virgin Islands. ${ }^{\dagger \dagger}$ This report includes data from 21 jurisdictions ${ }^{\$ \$}$ that implemented the optional family planning module on self-reported contraceptive use during September-December 2016.99 Individual contraceptive methods from this module were classified according to first-year typical use failure rates as most effective ( $\leq 1 \%$ failure), moderately effective ( $>1 \%-10 \%$ failure), or less effective $(>10 \%$ failure). ${ }^{* * *}$ Women reporting more than one contraceptive method were classified according to the most effective method they reported using.

Weighted estimates and 95\% confidence intervals were calculated to determine the proportion of women aged 18-49 years at risk for unintended pregnancy (defined as those who reported they were sexually active with a male partner, but did not report that they were currently pregnant or seeking

\footnotetext{
${ }^{\dagger \dagger}$ https://www.cdc.gov/brfss/data_documentation/index.htm.

$\$ \$$ Includes Alabama, Arizona, California, Connecticut, Florida, Georgia, Illinois, Kansas, Kentucky, Louisiana, Maryland, Minnesota, New Jersey, Ohio, Oklahoma, South Carolina, Texas, Virginia, West Virginia, Guam, and Puerto Rico. Data collected for Mississippi are not included in this report because they did not meet BRFSS reliability standards (denominators $\geq 50$ respondents and a relative standard error $\leq 30 \%$ ) with respect to reporting the number of women with ongoing or potential need for contraceptive services, or the proportion of women at risk for unintended pregnancy by method type.

99 Questions implemented followed those implemented in 2017 with Module 17: Preconception Health/Family Planning. https://www.cdc.gov/ brfss/questionnaires/pdf-ques/2017_BRFSS_Pub_Ques_508_tagged.pdf.

*** Most effective contraceptive methods included permanent contraceptive methods (female sterilization or report of male partner vasectomy) and longacting reversible contraception (LARC, including intrauterine devices [IUDs] and contraceptive implants). Moderately effective contraceptive methods included contraceptive injectables, contraceptive pills, contraceptive patches, and vaginal rings. Less effective contraceptive methods included diaphragms, condoms (male or female), withdrawal, cervical caps, sponges, spermicides, fertility-awareness based methods, and emergency contraception.
} 
pregnancy, that they would not mind being pregnant, or that they had a hysterectomy). In addition, numbers and rates (total number and number per 1,000 women aged 18-49 years) and corresponding $95 \%$ confidence intervals were calculated for women with ongoing or potential need for contraceptive services (defined as those at risk for unintended pregnancy who were not using permanent contraceptive methods [female sterilization or report of male partner vasectomy]). Estimates also were calculated to describe the proportion of women at risk for unintended pregnancy using contraception by effectiveness category (most effective, including permanent methods and long-acting reversible contraception [LARC]; moderately effective; less effective; and no method). Estimates for using either a less effective method or no method were further stratified by age group (18-24, 25-34, 35-44, and 45-49 years). Women at risk for unintended pregnancy who did not specify the type of contraception they used or reported "other" methods $(4.8 \%)^{\dagger \dagger \dagger}$ were excluded from estimates of contraceptive use by method

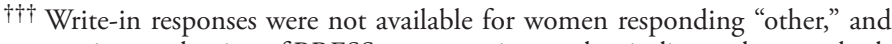
previous evaluation of BRFSS contraceptive use data indicates these methods are a mix of permanent and reversible methods of all effectiveness levels. https://www.cdc.gov/mmwr/volumes/65/wr/mm6530e2.htm.
}

effectiveness and from estimates of the number of women with ongoing or potential need for contraceptive services. Estimates that did not meet reliability standards established for BRFSS were suppressed. $\$ \$ \$$

Among the 21 jurisdictions, the proportion of women aged 18-49 years at risk for unintended pregnancy ranged from $57.4 \%$ (Texas) to $76.8 \%$ (Minnesota) (Table 1). Jurisdictions with the fewest numbers of women with ongoing or potential need for contraceptive services included Guam, Kansas, Puerto Rico, and West Virginia; jurisdictions with the highest numbers included California, Florida, Illinois, and Texas. Estimates of the number of women with ongoing or potential need for contraceptive services per 1,000 women aged 18-49 years ranged from 368 in Puerto Rico to 617 in Maryland. Among women at risk for unintended pregnancy, the proportion using either a most or moderately effective contraceptive method ranged from $26.1 \%$ (Guam) to $65.7 \%$ (West Virginia) (Table 2); among 11 jurisdictions with reliable estimates for LARC, use ranged from $5.5 \%$ (Kansas) to $17.0 \%$ (Maryland). Among 18 jurisdictions with reliable estimates, the percentage of

\$\$\$ Reliability standards for BRFSS require suppression of estimates with an unweighted denominator of $<50$ respondents or a relative standard error $>30 \%$.

TABLE 1. Percentage of women aged 18-49 years at risk for unintended pregnancy* and numbers of women with ongoing or potential need for contraceptive services, ${ }^{\dagger,} \S$ by jurisdiction - Behavioral Risk Factor Surveillance System, 21 jurisdictions, September-December, 2016

\begin{tabular}{|c|c|c|c|c|}
\hline \multirow[b]{2}{*}{ Jurisdiction } & \multirow[b]{2}{*}{$\begin{array}{l}\text { Total no. of women } \\
\text { aged } 18-49 \text { years }\end{array}$} & \multirow{2}{*}{$\begin{array}{c}\% \text { of women aged } 18-49 \text { years } \\
\text { at risk for unintended } \\
\text { pregnancy }(95 \% \mathrm{Cl})\end{array}$} & \multicolumn{2}{|c|}{ Women with ongoing or potential need for contraceptive services } \\
\hline & & & No. $(95 \% \mathrm{Cl})^{9}$ & $\begin{array}{l}\text { No. per } 1,000 \text { aged } \\
18-49 \text { years }(95 \% \mathrm{Cl})\end{array}$ \\
\hline Alabama & $1,022,400$ & $64.6(56.9-71.6)$ & $418,200(342,500-498,400)$ & $409(335-487)$ \\
\hline Arizona & $1,400,300$ & $57.9(42.9-71.5)$ & $683,400(487,400-882,200)$ & $488(348-630)$ \\
\hline California & $8,585,800$ & $67.6(60.3-74.1)$ & $4,464,500(3,817,200-5,104,000)$ & $520(445-594)$ \\
\hline Connecticut & 737,700 & $67.2(51.5-79.9)$ & $378,800(283,900-472,400)$ & $514(385-640)$ \\
\hline Florida & $4,027,500$ & $59.9(53.4-66.1)$ & $1,803,900(1,566,300-2,047,500)$ & $448(389-508)$ \\
\hline Georgia & $2,252,800$ & $62.5(50.3-73.2)$ & $1,089,400(828,400-1,354,400)$ & $484(368-601)$ \\
\hline Illinois & $2,745,600$ & $74.1(63.9-82.1)$ & $1,675,800(1,380,200-1,944,600)$ & $610(503-708)$ \\
\hline Kansas & 588,900 & $71.9(66.8-76.5)$ & $297,100(262,900-331,300)$ & $505(446-563)$ \\
\hline Kentucky & 913,400 & $71.8(66.8-76.3)$ & $447,900(397,400-498,600)$ & $490(435-546)$ \\
\hline Louisiana & 997,700 & $62.1(44.0-77.3)$ & $387,800(227,600-576,400)$ & $389(228-578)$ \\
\hline Maryland & $1,299,200$ & $75.8(69.3-81.3)$ & $801,200(707,500-888,600)$ & $617(545-684)$ \\
\hline Minnesota & $1,126,900$ & $76.8(70.3-82.3)$ & $596,800(502,200-689,700)$ & $530(446-612)$ \\
\hline New Jersey & $1,862,500$ & $76.6(65.4-85.0)$ & $1,142,400(922,100-1,340,300)$ & $613(495-720)$ \\
\hline Ohio & $2,359,500$ & $61.5(52.9-69.4)$ & $1,105,200(907,800-1,306,900)$ & $468(385-554)$ \\
\hline Oklahoma & 805,100 & $65.8(58.5-72.5)$ & $376,800(318,000-436,600)$ & $468(395-542)$ \\
\hline South Carolina & $1,021,100$ & $70.3(62.7-76.9)$ & $548,300(461,100-633,400)$ & $537(452-620)$ \\
\hline Texas & $6,011,100$ & $57.4(47.4-66.9)$ & $2,435,800(1,888,700-3,025,200)$ & $405(314-503)$ \\
\hline Virginia & $1,813,800$ & $71.6(64.1-78.1)$ & $938,500(799,900-1,075,600)$ & $517(441-593)$ \\
\hline West Virginia & 360,400 & $67.6(61.4-73.3)$ & $158,200(136,700-180,300)$ & $439(379-500)$ \\
\hline Guam & 35,200 & $70.3(59.2-79.4)$ & $20,800(16,500-24,700)$ & $591(469-702)$ \\
\hline Puerto Rico & 795,700 & $63.7(58.8-68.4)$ & $292,900(255,600-332,200)$ & $368(321-417)$ \\
\hline
\end{tabular}

Abbreviation: $\mathrm{Cl}=$ confidence interval.

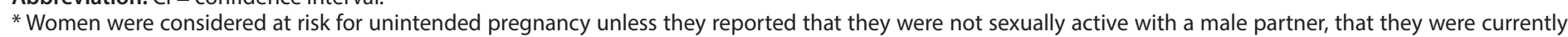
pregnant or seeking pregnancy, that they would not mind being pregnant, or that they had a hysterectomy.

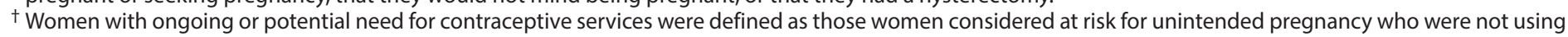
permanent contraceptive methods (female sterilization or report of male partner vasectomy).

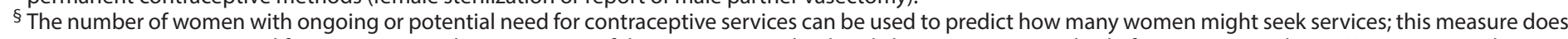

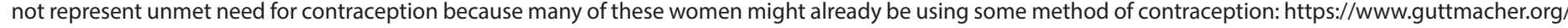
sites/default/files/report_pdf/contraceptive-needs-and-services-2014_1.pdf.

१ Numbers are rounded to the nearest 100. 
TABLE 2. Percentage of women aged 18-49 years at risk for unintended pregnancy* using most ${ }^{\dagger}$ or moderately effective $^{\S}$ contraceptive $^{*}$ methods, by jurisdiction - Behavioral Risk Factor Surveillance System, 21 jurisdictions, September-December, 2016

\begin{tabular}{|c|c|c|c|c|}
\hline \multirow[b]{3}{*}{ Jurisdiction } & \multirow{2}{*}{$\begin{array}{c}\text { Total } \\
\text { Most or moderately effective }\end{array}$} & \multicolumn{2}{|c|}{ Most effective } & \multirow[b]{2}{*}{ Moderately effective } \\
\hline & & Sterilization & Long-acting reversible (LARC) & \\
\hline & $\%(95 \% \mathrm{Cl})$ & $\%(95 \% \mathrm{Cl})$ & $\%(95 \% \mathrm{Cl})$ & $\%(95 \% \mathrm{Cl})$ \\
\hline Alabama & $63.8(54.0-72.5)$ & $35.7(26.6-46.0)$ & -9 & $19.1(12.5-28.2)$ \\
\hline Arizona & $39.1(25.1-55.1)$ & - & - & - \\
\hline California & $51.5(42.0-60.9)$ & $22.5(16.5-29.9)$ & $11.7(7.5-17.8)$ & $17.2(12.4-23.4)$ \\
\hline Connecticut & $55.4(44.5-65.9)$ & $21.9(15.0-31.0)$ & $9.4(5.5-15.7)$ & $24.1(14.6-37.0)$ \\
\hline Florida & $48.6(42.0-55.2)$ & $22.9(17.3-29.6)$ & $9.7(6.5-14.4)$ & $16.0(12.0-21.0)$ \\
\hline Georgia & $51.5(36.9-65.8)$ & $22.3(12.0-37.7)$ & - & - \\
\hline Illinois & $62.4(50.5-73.0)$ & $16.8(10.0-26.7)$ & - & $33.3(21.0-48.3)$ \\
\hline Kansas & $60.9(53.7-67.7)$ & $28.9(23.0-35.8)$ & $5.5(3.3-9.1)$ & $26.4(20.6-33.2)$ \\
\hline Kentucky & 60.1 (53.4-66.5) & $31.3(25.1-38.2)$ & $6.6(4.1-10.6)$ & $22.2(17.0-28.4)$ \\
\hline Louisiana & $56.9(32.1-78.7)$ & $35.0(18.7-55.8)$ & - & - \\
\hline Maryland & $62.3(53.8-70.1)$ & $17.6(12.7-23.9)$ & $17.0(11.0-25.4)$ & $27.7(19.5-37.6)$ \\
\hline Minnesota & $60.2(50.2-69.4)$ & $29.9(21.3-40.2)$ & $11.8(6.6-20.2)$ & $18.5(11.1-29.2)$ \\
\hline New Jersey & 50.8 (37.2-64.2) & $16.3(10.5-24.5)$ & - & - \\
\hline Ohio & $45.4(35.7-55.3)$ & $22.9(16.6-30.6)$ & $7.6(4.4-13.0)$ & $14.8(10.0-21.5)$ \\
\hline Oklahoma & $62.5(53.0-71.1)$ & $28.2(21.3-36.3)$ & - & $27.0(19.5-36.0)$ \\
\hline South Carolina & $61.5(50.3-71.7)$ & $22.8(15.5-32.3)$ & $10.5(5.8-18.3)$ & $28.2(19.4-39.2)$ \\
\hline Texas & $53.0(40.7-65.1)$ & $27.3(17.7-39.5)$ & - & $20.5(12.8-31.1)$ \\
\hline Virginia & $60.8(51.9-68.9)$ & $26.8(20.0-35.0)$ & $13.3(7.8-21.7)$ & $20.7(14.8-28.0)$ \\
\hline West Virginia & 65.7 (58.9-72.0) & $34.4(27.8-41.6)$ & $11.0(6.5-17.9)$ & $20.4(15.0-27.0)$ \\
\hline Guam & $26.1(15.2-41.0)$ & - & - & - \\
\hline Puerto Rico & $49.8(43.6-55.9)$ & $41.6(35.7-47.8)$ & - & $6.8(4.1-11.1)$ \\
\hline
\end{tabular}

Abbreviation: $\mathrm{Cl}=$ confidence interval

* Women were considered at risk for unintended pregnancy unless they reported that they were not sexually active with a male partner, that they were currently pregnant or seeking pregnancy, that they would not mind being pregnant, or that they had a hysterectomy.

$\dagger$ Most effective contraceptive methods included permanent methods (female sterilization or report of male partner vasectomy) and long-acting reversible contraception (LARC, including intrauterine devices [IUDs] and contraceptive implants); most effective methods have a $\leq 1 \%$ failure rate during the first year of typical use. Sources: Trussell J. Contraceptive failure in the United States. Contraception 2011;83:397-404. Sundaram A, Vaughan B, Kost K, et al. Contraceptive failure in the United States: estimates from the 2006-2010 National Survey of Family Growth. Perspect Sex Reprod Health 2017;49:7-16.

$\S$ Moderately effective contraceptive methods included contraceptive injectables, contraceptive pills, transdermal contraceptive patches, and vaginal rings; moderately effective methods have a $>1 \%-10 \%$ failure rate with typical use. Sources: Trussell J. Contraceptive failure in the United States. Contraception 2011;83:397-404. Sundaram A, Vaughan B, Kost K, et al. Contraceptive failure in the United States: estimates from the 2006-2010 National Survey of Family Growth. Perspect Sex Reprod Health 2017;49:7-16.

? Estimate is unreliable (relative standard error $>30 \%$ or denominator $<50$ ).

women at risk for unintended pregnancy using a less effective method of contraception ranged from $11.1 \%$ (Illinois) to $47.7 \%$ (Arizona), and among 19 jurisdictions, the percentage not using any method of contraception ranged from $16.5 \%$ (Virginia) to $63.0 \%$ (Guam) (Table 3). Across age-stratified estimates, the percentage using either a less effective method or no method ranged from $25.9 \%$ (women aged 35-44 years in South Carolina) to $79.9 \%$ (women aged 18-24 years in California) (Supplementary Table, https://stacks.cdc.gov/ view/cdc/57915).

\section{Discussion}

Across the 21 jurisdictions, the number of women with ongoing or potential need for contraceptive services per 1,000 women aged 18-49 years ranged from 368 to 617 and exceeded 4 million in total in the jurisdiction with the highest number of women with ongoing or potential need for contraceptive services. The proportion of women at risk for unintended pregnancy using a most or moderately effective method of contraception ranged from $26.1 \%$ to $65.7 \%$. The proportion using no contraception ranged from $16.5 \%$ to $63.0 \%$. These data can be used for jurisdictional planning and are particularly important in the context of public health emergencies associated with increased risk for adverse maternal-infant outcomes that heighten the need to provide women and their partners with resources to prevent unintended pregnancy.

The data for this report were collected because of concerns about Zika virus-related adverse pregnancy and birth outcomes; however, the findings have broader implications. Several types of public health emergencies, such as natural disasters, including hurricanes, have been associated with adverse maternal-infant outcomes, along with disruptions in women's abilities to access contraception and interruptions in method use $(4,5)$. Similarly, given the ongoing opioid crisis and high proportion of unintended pregnancies among women who misuse opioids (G), ensuring access to contraception and preconception care among these women is an important strategy for reducing the incidence of neonatal abstinence syndrome (๑). Moreover, ensuring access to effective contraception is important in general for supporting women and their 
TABLE 3. Percentage of women aged 18-49 years at risk for unintended pregnancy* ${ }^{*}$ using less effective ${ }^{\dagger}$ contraceptive methods or no method, by jurisdiction - Behavioral Risk Factor Surveillance System, 21 jurisdictions, September-December, 2016

\begin{tabular}{|c|c|c|c|}
\hline \multirow[b]{3}{*}{ Jurisdiction } & \multicolumn{2}{|l|}{ Total } & \multirow[b]{2}{*}{ No method } \\
\hline & $\begin{array}{l}\text { Less effective or } \\
\text { no method }\end{array}$ & $\begin{array}{l}\text { Less effective } \\
\text { method }\end{array}$ & \\
\hline & $\%(95 \% \mathrm{Cl})$ & $\%(95 \% \mathrm{Cl})$ & $\%(95 \% \mathrm{Cl})$ \\
\hline Alabama & $36.2(27.5-46.0)$ & $13.6(8.3-21.6)$ & $22.6(15.6-31.6)$ \\
\hline Arizona & $60.9(44.9-74.9)$ & $47.7(31.0-65.0)$ & $-\S$ \\
\hline California & $48.5(39.1-58.0)$ & $31.6(21.9-43.2)$ & $16.9(12.3-22.9)$ \\
\hline Connecticut & $44.6(34.1-55.5)$ & $20.4(13.0-30.6)$ & $24.1(16.4-34.1)$ \\
\hline Florida & $51.4(44.8-58.0)$ & $14.1(10.2-19.3)$ & $37.3(31.2-43.9)$ \\
\hline Georgia & $48.5(34.2-63.1)$ & - & $34.1(21.9-48.8)$ \\
\hline Illinois & $37.6(27.0-49.5)$ & $11.1(6.2-19.1)$ & $26.4(18.0-37.0)$ \\
\hline Kansas & 39.1 (32.3-46.3) & $14.5(10.4-19.8)$ & $24.6(18.7-31.7)$ \\
\hline Kentucky & 39.9 (33.5-46.6) & $20.0(15.0-26.1)$ & $19.9(15.5-25.2)$ \\
\hline Louisiana & $43.1(21.3-67.9)$ & - & - \\
\hline Maryland & $37.7(29.9-46.2)$ & $18.8(13.3-26.0)$ & $18.9(13.4-25.8)$ \\
\hline Minnesota & $39.8(30.6-49.8)$ & $13.1(8.1-20.6)$ & $26.7(19.0-36.1)$ \\
\hline New Jersey & $49.2(35.8-62.8)$ & $18.3(10.7-29.6)$ & $30.9(21.3-42.5)$ \\
\hline Ohio & $54.6(44.7-64.3)$ & $22.2(13.0-35.2)$ & $32.5(23.5-43.0)$ \\
\hline Oklahoma & $37.5(28.9-47.0)$ & $11.8(7.9-17.3)$ & $25.7(17.8-35.6)$ \\
\hline South Carolina & $38.5(28.3-49.7)$ & $11.3(7.7-16.3)$ & $27.2(17.6-39.5)$ \\
\hline Texas & $47.0(34.9-59.3)$ & $16.0(9.8-24.9)$ & $31.0(19.7-45.0)$ \\
\hline Virginia & $39.2(31.1-48.1)$ & $22.7(15.6-31.8)$ & $16.5(11.9-22.4)$ \\
\hline West Virginia & $34.3(28.0-41.1)$ & $11.9(8.4-16.7)$ & $22.3(17.2-28.5)$ \\
\hline Guam & $74.0(59.0-84.8)$ & - & $63.0(47.7-76.0)$ \\
\hline Puerto Rico & $50.2(44.1-56.4)$ & $20.1(15.5-25.6)$ & $30.2(24.8-36.1)$ \\
\hline
\end{tabular}

Abbreviation: $\mathrm{Cl}=$ confidence interval.

* Women were considered at risk for unintended pregnancy unless they reported that they were not sexually active with a male partner, that they were currently pregnant or seeking pregnancy, that they would not mind being pregnant, or that they had a hysterectomy.

${ }^{\dagger}$ Less effective contraceptive methods included diaphragms, condoms (male or female), withdrawal, cervical caps, sponges, spermicides, fertility-awareness based methods, and emergency contraception; less effective methods have a $>10 \%$ failure rate during the first year of typical use. Sources: Trussell J. Contraceptive failure in the United States. Contraception 2011;83:397-404. Sundaram A, Vaughan B, Kost K, et al. Contraceptive failure in the United States: estimates from the 2006-2010 National Survey of Family Growth. Perspect Sex Reprod Health 2017;49:7-16.

$\S$ Estimate is unreliable (relative standard error $>30 \%$ or denominator $<50$ ).

partners in planning their pregnancies and is also cost-saving (7), particularly during public health emergencies such as the Zika virus outbreak where costs associated with long-term care of children with adverse birth outcomes are high (8).

Jurisdiction-level data are important because of the substantial variation among jurisdictions in unintended pregnancy rates (9). Although a number of sociodemographic factors contribute to this variation, implementation of programs and policies that increase access to contraception, including the most effective methods, also varies considerably among jurisdictions.999 During the Zika virus outbreak response,

\footnotetext{
999 Examples of programs and policies that vary by state include participation in the Association of State and Territorial Health Officials' state learning community for improving access http://www.astho.org/Programs/Maternaland-Child-Health/Increasing-Access-to-Contraception/ and Medicaid family planning eligibility expansions https://www.guttmacher.org/state-policy/ explore/medicaid-family-planning-eligibility-expansions.
}

CDC worked with jurisdictional partners to implement strategies to promote increased access to contraception (3). Frequently adopted strategies included maintaining sustainable partnerships among insurers, manufacturers, and state agencies; reimbursing for the full range of contraceptive services; maintaining continuous stocking and supply of devices in a wide range of service facilities; and training providers on current insertion and removal techniques for the most effective methods. Although developed during the Zika virus response, these strategies apply broadly to all situations in which women and their partners need access to resources to prevent unintended pregnancy.

This report provides data both for estimating the number of women who might seek services and for evaluating the impact of policies and programs. Understanding how many women need contraceptive services and where the need is greatest can aid in planning health care delivery.*** In addition, the proportion of women at risk for unintended pregnancy using a most or moderately effective contraceptive method is an established indicator of quality family planning service provision ${ }^{\dagger+\dagger}$ and a Healthy People 2020 objective. $\$ \$ \$ \$$ This indicator is critical for evaluating the success of implementation strategies and population-level impact (1). Conversely, variation in prevalence of use of less effective contraceptive methods or no method, as documented in this report by age group, can be used to identify the need for targeted implementation of strategies, such as provision of youth-friendly services (3).

The findings in this report are subject to at least five limitations. First, information on contraceptive use was self-reported and might be subject to recall or social desirability bias. Second, because data for this report were collected over a 4-month period versus an entire year, small sample sizes limited the precision of estimates. Third, it was not possible to determine whether those reporting unspecified methods were using permanent or reversible methods. Estimates of the number of women with ongoing or potential need for contraceptive services therefore excluded these women and might have underestimated the number who might seek services; conversely, these estimates included women using LARC, who might only need services every 3-10 years depending on the type of LARC (10). Fourth, this report includes data from only 21 jurisdictions and is not representative of other jurisdictions; however, it highlights the need for ongoing collection of jurisdiction-level data for all U.S. jurisdictions. Finally, nonresponse bias remains a possibility, although the weighting methodology used by BRFSS adjusts for nonresponse bias.

\footnotetext{
**** https://www.guttmacher.org/sites/default/files/report_pdf/contraceptiveneeds-and-services-2014_1.pdf and https://thenationalcampaign.org/deserts.

††† https://www.hhs.gov/opa/performance-measures/most-or-moderatelyeffective-contraceptive-methods/index.html.

$\$ \mathbb{S} \$$ https://www.healthypeople.gov/2020/topics-objectives/topic/familyplanning/objectives; FP-16.
} 


\section{Summary}

What is already known about this topic?

Ensuring access to contraception is an effective strategy for preventing unintended pregnancy and associated negative maternal-infant outcomes.

\section{What is added by this report?}

Data from 21 jurisdictions collected during a 4-month period indicated the number of women with ongoing or potential need for contraceptive services per 1,000 women aged 18-49 years. ranged from 368 to 617 . The proportion at risk for unintended pregnancy using a most or moderately effective contraceptive method ranged from $57.4 \%$ to $76.8 \%$. The proportion using no contraception ranged from $16.5 \%$ to $63.0 \%$.

What are the implications for public health practice?

The recent Zika virus outbreak highlighted the need for contraception data in the context of public health responses associated with adverse maternal-infant outcomes. These data can inform delivery of contraceptive services and evaluation of implementation strategies to increase access to contraception.

Ensuring access to effective contraception is an important strategy for preventing unintended pregnancy and can be particularly important in the context of certain public health responses. During the Zika virus outbreak, contraception served as a medical countermeasure to prevent Zika virus-affected pregnancies and is similarly important in other contexts where risk for adverse maternal-infant outcomes is increased. The data in this report can be applied in nonemergency settings to help jurisdictions estimate the number of women who might seek contraceptive services and to plan and evaluate implementation strategies.

\section{Acknowledgments}

Robert Bailey, Arizona Department of Health Services; Judy Bass, Arizona Department of Health Services; Gayle Blair, Illinois Department of Public Health; Martin F. Celaya, Arizona Department of Health Services; Elizabeth Ferree, Virginia Department of Health; William Garvin, Division of Population Health, National Center for Chronic Disease Prevention and Health Promotion, CDC; Jennifer G. Laliberté, Kansas Department of Health and Environment; Tebitha Mawokomatanda, Division of Population Health, National Center for Chronic Disease Prevention and Health Promotion, CDC; Kenneth J. O'Dowd, New Jersey Department of Health; Ghazala Perveen, Kansas Department of Health and Environment.

\section{Behavioral Risk Factor Surveillance System Family Planning Module Working Group}

Leah Atwell, Florida Department of Health; Rana Bayakly, Georgia Department of Public Health; Sarah Conklin, Virginia Department of Health; Harley T. Davis, South Carolina Department of Health and Environmental Control; Victoria Davis, Georgia Department of Public Health; Laurie Freyder, Louisiana Department of Health; Christine Graham, Louisiana State University; Sarojini Kanotra,
Kentucky Department for Public Health; Sarah Khalidi, Alabama Department of Public Health; Georgette Lavetsky, Maryland Department of Health; Kristi Pier, Maryland Department of Health; Lauren Porter, Florida Department of Health; Mina Qobadi, Mississippi State Department of Health; Sondra Reese, Alabama Department of Public Health; Chelsea L. Richard, South Carolina Department of Health and Environmental Control; Nagi Salem, Minnesota Department of Health; Ruby A. Serrano-Rodríguez, Puerto Rico Department of Health; Birgit A. Shanholtzer, West Virginia Department of Health and Human Resources; Holly Sobotka, Ohio Department of Health; Amilcar Soto-Mercado, Puerto Rico Department of Health; Carol L. Stone, Connecticut Department of Public Health.

\footnotetext{
${ }^{1}$ Division of Reproductive Health, National Center for Chronic Disease Prevention and Health Promotion, CDC; ${ }^{2}$ Division of Congenital and Developmental Disorders, National Center on Birth Defects and Developmental Disabilities.

Corresponding author: Karen Pazol, kpazol@cdc.gov, 770-488-6305.
}

\section{Conflict of Interest}

No conflicts of interest were reported.

\section{References}

1. Rankin KM, Gavin L, Moran JW Jr, et al. Importance of performance measurement and $\mathrm{MCH}$ epidemiology leadership to quality improvement initiatives at the national, state and local levels. Matern Child Health J 2016;20:2239-46. https://doi.org/10.1007/s10995-016-2105-y

2. Rasmussen SA, Jamieson DJ, Honein MA, Petersen LR. Zika virus and birth defects - reviewing the evidence for causality. N Engl J Med 2016;374:1981-7. https://doi.org/10.1056/NEJMsr1604338

3. Kroelinger CD, Romero L, Lathrop E, et al. Meeting summary: state and local implementation strategies for increasing access to contraception during Zika preparedness and response_-United States, September 2016. MMWR Morb Mortal Wkly Rep 2017;66:1230-5. https://doi. org/10.15585/mmwr.mm6644a6

4. Ellington SR, Kourtis AP, Curtis KM, et al. Contraceptive availability during an emergency response in the United States. J Womens Health (Larchmt) 2013;22:189-93. https://doi.org/10.1089/jwh.2012.4178

5. Callaghan WM, Rasmussen SA, Jamieson DJ, et al. Health concerns of women and infants in times of natural disasters: lessons learned from Hurricane Katrina. Matern Child Health J 2007;11:307-11. https:// doi.org/10.1007/s10995-007-0177-4

6. Ko JY, Wolicki S, Barfield WD, et al. CDC grand rounds: public health strategies to prevent neonatal abstinence syndrome. MMWR Morb Mortal Wkly Rep 2017;66:242-5. https://doi.org/10.15585/mmwr. mm6609a2

7. Frost JJ, Sonfield A, Zolna MR, Finer LB. Return on investment: a fuller assessment of the benefits and cost savings of the US publicly funded family planning program. Milbank Q 2014;92:696-749. https://doi. org/10.1111/1468-0009.12080

8. Li R, Simmons KB, Bertolli J, et al. Cost-effectiveness of increasing access to contraception during the Zika virus outbreak, Puerto Rico, 2016. Emerg Infect Dis 2017;23:74-82. https://doi.org/10.3201/ eid2301.161322

9. Finer LB, Kost K. Unintended pregnancy rates at the state level. Perspect Sex Reprod Health 2011;43:78-87. https://doi.org/10.1363/4307811

10. Committee on Practice Bulletins-Gynecology, Long-Acting Reversible Contraception Work Group. Practice bulletin no. 186: long-acting reversible contraception: implants and intrauterine devices. Obstet Gynecol 2017;130:e251-69. 